\title{
Det andre spillet
}

\section{Øyvind Aase}

Kulturfolk etterstreber en kunst hinsides hverdagen, og i lengselen etter noe annet enn standardkunsten dyrkes visjonen om den utilnærmelige kunstneren. Det originale i musikkutøvelsen opptrer da også som uttrykk for en avstand. Men hvorvidt den andre kunsten finnes rundt neste gatehjørne, eller befinner seg lysår unna, kan være én og samme sak. 


\section{Musikk for andre ører}

Høsten 2002 kunne menneskeheten feire et foreløpig jubileum for det en amerikansk forsker kalte "vår tids største seier". Da var det gått 25 år siden amerikanerne sendte romsondene Voyager 1 og Voyager 2 ut på en evig reise i verdensrommet. På sin ferd ut av solsystemet har fartøyene gjort stadig nye oppdagelser i rommet, formidlet via et omfattende billedmateriale. Våre gjenytelser til universet vil på sin side være mer for øret enn for øyet. Romsondene skal være rikelig ekvipert med det ypperste planeten Tellus kan by på av kunst og kultur. Med på ferden er eksempler på en rekke av jordens språk, et utvalg av jordens lyder, vestlig kunstmusikk, syngende jenter fra Zaire og japansk fløytemusikk. Materialet kan oppleves via en platespiller med vedlagt instruksjonshefte. Hvis det er intelligent liv der ute, vil "deres" opplevelse av vårt kulturgods fortone seg slik, ifølge en norsk avis: "Vertskapet kan sette hodetelefoner på de små, grønne ørene sine og lytte til verker av Johann Sebastian Bach, Wolfgang Amadeus Mozart - og Chuck Berry."

Gitt korrekt farge og størrelse på ørene, vil de fremmede i så fall kunne låne dem til den canadiske pianisten Glenn Goulds tolkning av Bachs "Preludium og Fuge i C-dur", som er blant de utsendte lydeksemplene. Og med tanke på Goulds ry som det jordiske klaverspillets mest sfærisk anlagte utøver, virker det naturlig at nettopp han kan bli den som, flerfoldige lysår foran konkurrentene, innvier utenomjordiske vesener i klaverkunstens mysterier. Som en osloavis formulerte det i 1994, i forbindelse med norgeslanseringen av Francois Girards 32 korte filmer om Glenn Gould: "Dermed kan andre romvesener få vite at det finnes sivilisert liv på den fjerne planeten Tellus." ${ }^{2}$

\section{Richter i Oslo}

Innenfor den vestlige, klassiske musikktradisjonen fikk instrumentalmusikken økt betydning ved inngangen til romantikken. Ludwig Tieck, et av de viktigste talerørene for den spekulative musikkestetikken, fremmante bildet av en musikk for seg selv, frigjort fra rasjonalismens jordbundethet. Denne musikken "oppfyller det høyeste krav, den følger sin dunkle drift og uttrykker det dypeste, det vidunderligste med sin lek."3 Blant instrumentalistene ble den gudbenådede pianisten tidlig utsett til å realisere det romantiske programmet i praksis.

Sommeren 1993 - året før en norsk avis så klaverkunsten som

1 avis 1, 22/8 2002 .

2 Arbeiderbladet, 2/9 1994.

3 Sitert fra Benestad. 
del av et kosmisk dannelsesprosjekt - hadde oslopressen allerede hatt sin egen dannelseskampanje gående for å redde byens kulturelle rykte. For Oslos konsertpublikum gikk dengang fremmede romvesener en høy gang i sin uvitenhet om en av tidens store fremtoninger på klavermusikkens stjernehimmel. Det var en julidag det året at Aftenposten kunne fortelle leserne om "den legendariske russiske pianisten Svjatoslav Richter", som hadde meldt sin ankomst til hovedstaden noen uker senere.

"Spillet er hinsides alt ... han er en totalopplevelse", ${ }^{4}$ sa platespaltisten Kjell Hillveg i gamle Tiecks ånd da besøket nærmet seg. Direktør August Albertsen i Den Gamle Logen hadde først reagert akkurat slik vi forestiller oss at folk på en fremmed planet vil respondere på uventede visitter, for han fikk seg ifølge en avis "ikke riktig til å tro på de første meldingene". Men direktøren kjente ellers godt til den fremmede kometen med fart mot Oslo. Da var det langt verre fatt med byens konsertgjengere, som stilte seg ganske likegyldig til fenomenet Richter. Billettsalget gikk usedvanlig tregt. Arrangørene bet negler. Da Richters ankomst begynte å nærme seg, var det ingen utvei lenger: Pressen tok saken.

\section{Hinsides konkurrenter og publikum}

Året før det norske folk for annen gang valgte å stå utenfor det europeiske fellesskapet, så Jan E. Hansen i Aftenposten den norske Richter-vegringen som et karakteristisk utslag av nordmenns generelle angst for alt ukjent utenlandsk som smaker av skolering og en høyt utviklet kultur:

I egenskap av levende legende i kunstens verden frister han [Richter] ytterst få nordmenn. Det kan ha noe med uvitenhet å gjøre. ... Er det navnet hans som skremmer? Vi vet av erfaring fra Vinmonopolets salgsstatistikker at selv gode varer til en rimelig penge har en tendens til å bli stående i reolen, dersom de har navn det er vanskelig å uttale over disk uten fransk mellomfag. ... I et land hvor Svjatoslav Richter risikerer å spille for halv salong, er det rart at det finnes opera overhodet. ${ }^{5}$

Hillveg mente Richter hadde "signert noen av de utroligste klaverdokumenter som noen sinne er festet på plate", og at når "Richter ønsker å spille i Norge ... skal vi gå mann av huse. ... Når den store Richter beærer oss med sitt nærvær, bør vi svare med overfylte saler."

Nå er det vanskelig å skrive om musikk, og enda vanskeligere

4 Dagbladet, $15 / 81993$.

5 Aftenposten, 17/8 1993.

6 Aftenposten, 14/8 1993. er det å begrunne hvorfor "det beste" er bedre enn "alt annet". Begeistringen søker gjerne tilflukt i et groupie-preget, prokla- 
merende språk, som kler korsfarere og misjonærer bedre enn pressens frie ånder. Hansen og Hillveg brenner for et annet spill enn det vanlige, men vi får ikke tak i hva dette andre er for noe, hva det betyr og innebærer i en genuin musikalsk kontekst. "Det viktigste er musikken", hevdet pianisten Kjell Bækkelund, uten å gi påstanden en språkføring vi kunne lære av. Det nærmeste han kom en beskrivelse av Richters egenart, var av parapsykologisk natur, som da han erindret hans konsert i Oslo år tilbake, "hvor den fullsatte sal opplevet det merkeligelektrifiserende på forhånd." Da Richter entret scenen, og fikk øye på en overivrig pressefotograf, ble magien håndhevet med en gurus utstråling: "Salen så at Richter oppdaget ham. En magisk pekefinger bare befalte fotografen å forlate salen. ... vi som opplevet det, glemmer det ikke, det var et møte med den store autoritet." ${ }^{7}$ Pianisten Leif Ove Andsnes hadde heller ikke noe vesentlig å fortelle om hvor det unike i mesterens spill egentlig lå ("når jeg hører Richter spille, føler jeg at ja, slik skal det være"), men var ikke desto mindre på sporet av noe da han resonnerte omkring sin eldre kollegas publikumsvegring: "Han kommer inn på podiet, bukker stivt og nesten militært ... Man får følelsen av at han helst ikke vil ha noe med oss å gjøre."

\section{Skjult for verden}

Oslopublikummet møtte til slutt mannssterkt opp for å lytte til musikeren som forlot denne verden i 1997. I 1998 viste NRK Bruno Monsaingeons dokumentarfilm, Richter the Enigma. Filmen starter med følgende beskrivelse av legenden: "Richter er en verden for seg selv, ugjennomtrengelig, men strålende; en dypvannsfisk; blind, men strålende." Bildet er treffende, og stemmer med Andsnes `fornemmelse av en pianist som på podiet ter seg som om han beveger seg i feil element, og som bare motvillig søker til overflaten for å møte et publikum som tiltrekkes ytterligere av mesterens avstand. Dynamikken i denne fascinasjonen kan til tider svekke konsentrasjonen om verket selv, ifølge musikkanmelderen Ståle Wikshåland: "anledningen til å høre Richter spille, får deg nesten til å glemme hva utgangspunktet var."

Richter er ute av tiden nå, og det er også Glenn Gould, som gikk bort i 1982. Mens førstnevnte var dypvannsfisken som ved sjeldne anledninger strålte foran sine fjerne slektninger blant menneskene, tok sistnevnte i en alder av rundt tretti år sitt definitive farvel med det levende konsertlivet for å virke gjennom lydmedi-

ets nye verden av muligheter. Fra sitt musikalske refugium bidro

7 Aftenposten, 18/8 1993.

8 Aftenposten, 21/8 1993.

9 Dagbladet, 26/8 1993. 
pianisten til en annerledes forståelse av spillets egenart, i trygg avstand fra det Edward W. Said omtaler som "the social abnormality of the concert ritual". I sin roman Havaristen skildrer Thomas Bernhard flukten fra podiet som et uttrykk for klaverspillerens hat til publikum og virtuosrollen:

Han var den eneste verdensberømte klavervirtuos som avskydde sitt publikum og som faktisk og definitivt hadde trukket seg tilbake fra dette avskydde publikum. ... Konsertvirksomhet er det frykteligste man kan tenke seg, ... spiller vi klaver for et publikum, er det redselsfullt, ... Og Glenn [Gould] spilte jo også bare et par-tre år offentlig, så tålte han det ikke lenger og ble der, i huset sitt i Amerika, han den beste og viktigste av alle klaverspillere.

\section{Publikums verden}

Den "beste" klaverspilleren er den som lever i skjul for sitt publikum. Richter og Gould representerte i så måte variasjoner over ett og samme tema: Forestillingen om åndsmennesket som skyr larmen i det offentlige kulturlivet, for å isolere seg i skapende kontakt med et eget, indre og "annet" kosmos. Slik kunne f.eks. den polske dikteren Witold Gombrowicz i 1953 skildre hvordan han opplevde klaverspillet i dets mest larmende utgave, når han etter å ha overværet en konsert i Colon, bekjenner seg til dagboksidene etter et utmattende møte med det amerikanerne kaller "war-horses"; her kjente klaverkonserter som i sin populære velde meier ned et motstandsløst publikum (sitert i dansk oversettelse):

Var det mon en pianist eller var det en hest? Jeg ville have svoret på at her drejede det sig ikke om Mozart, men blot om hvorvidt denne letfodede ganger kunne tøjle Horowitz eller Rubinstein. ... Jeg var til boksekamp, og jeg så ham ... hamre løs på Gieseking med sit oktavspil, give Solomon et knock-out med sin trille. Pianist, hest, bokser? Så forekom det mig at det var en bokser der svang sig op på Mozart, der red på Mozart, der piskede og slog løs på Mozart og trommede og prikkede på ham med sporerne.

I sin bok Musical Elaborations beskriver Edward W. Said "modern musical performance [som] rather like an athletic event in its demand for the admiringly rapt attention of its spectators." Det er nettopp det utenommusikalske ved konserten som "occasion" som interesserer ham, for "there is an enduring ... quality to certain aspects of the performance, interpretation, and production of Western classical music that can be studied and examined 
precisely because the integrity and specialization involved nevertheless converge upon other cultural and theoretical issues ... that do not belong completely to the sphere of music." I kapitlet, som bærer tittelen Performance as an Extreme Occasion, påpeker han videre at den offentlige konserten som historisk fenomen "can be interpreted as a cultural occasion staked upon specialized eccentric skills, ... What competes with these occasions is ... other public displays of specialized skill (sports, circus, dance contests) that, at its worst and most vulgar, the concert may attempt to match".

For Said ligger nettopp noe av det unike ved den offentlige utøvelsen av musikk i konsertens ekstreme natur, for dens "narcissistic, self-referential, ... self-consultive qualities, is the central and most socially stressed musical experience in modern Western society". Og siden aktørenes (musikere og publikum) erfaring forutsetter og overlapper hverandre, spør Said hvilken type symbiose vi her står overfor. Svaret finner han i tilfellet Toscanini. Said godtar for så vidt Adornos kritikk av denne dirigentens hang til innøvet dynamikk og andre på forhånd fastsatte sider ved tolkningene, hans favorisering av melodistemmen i Wagner og hans tendens til å "rense" partiturene for deres kontrapunktiske (flerstemmige), komplekse tekstur, hvor andre dirigenter gir mer adekvate tolkninger av verkene som verker betraktet. Men for Said teller det mer at "Toscanini's work clarified what is extreme about the concert occasion itself." Maestroens fremførelse av Beethovens Eroica-symfoni, som - renset som den er for alle tilløp til sentimentalitet, rubato, innsmigrende utbrodering og dvelende nostalgi - setter i så måte "the utterly contrary quality of the performance occasion, its total discontinuity with the ordinary, regular, or normative processes of everyday life" i den absolutte forgrunnen. Toscaninis fremførelser må i denne forstand forstås som begivenheter som "stems immediately from what is extreme in the occasion itself".

\section{Musikken som påskudd}

Ikke uventet møter slike synspunkter sterkest motbør fra skjønnlitterært hold. For Saids forelskede nærblikk på fremførelsens psykologi, innebærer i siste instans en nedgradering av kunstverkets egenverdi, hvilket uvilkårlig reduserer tonekunstens potensial som metafor for det sublime i litteraturen. Ikke for ingenting foreslår den franske forfatteren Guy Scarpetta å bruke betegnelsen "pianistisk" om Thomas Bernhards skrivemåte, som 
da kjennetegnes av "modulasjoner, repriser, forandringer i intensitet, rytmisk puls, som til en viss grad minner om Glenn Goulds kunst når han tolker Bach".

Og Bernhard selv viser nettopp i sin Gould-fiksjon hvor maktpåliggende det er for ham å markere avstand til den utadvendte, publikumsvennlige standardpianisten, som blir en negativ motpol til en annen og sannere klaverspiller. Gould-skikkelsen blir et emblem for denne "andre" musikertypen. Fortelleren i Havaristen, som retter sine utfall mot virtuosrollen, som igjen er knyttet til konsertformen, formulerer sin antipati mot sistnevnte ved å sondre mellom to typer av klaverspillere. Han avviser ettertrykkelig "det motbydelige pianist"; han foretrekker i stedet betegnelsen klaverkunstner. Bare tanken på "pianister" fremkaller bitre minner om lærerne fra studietiden, "som alle ... hadde lysende navn, som til stadighet opptrådte i de store byene ... men de er ikke annet enn pianospillende ødeleggere, som ikke har peiling på musikkbegrepet".

I Thomas Manns roman Doktor Faustus har den kommende komponisten Adrian Leverkühn skrupler i forhold til konvensjonens tendens til å ville beherske musikken. Konsertritualets utenommusikalske komponenter gir ham anselige kvaler foran valg av profesjon: "Han var ikke kommet til tastaturet av lyst til å oppkaste seg til herre over det, men av skjult nysgjerrighet på musikken selv, og han manglet helt og holdent sigøynerblodet til den konserterende kunstner, som nærmest brukte musikken som påskudd til å få utgyte seg for et publikum." Nå startet Leverkühn for sent å spille klaver, men "selv om det ikke hadde vært for sent for ham å bli pianist, ville han vært for ærbar, for stolt, for blyg, for ensom for virtuositeten". Denne kombinerte stolthet og blyghet blir senere i boken utlagt som et uttrykk for "alvorets ressentiment mot verdens salong".

\section{Horowitz ved klaveret}

I sitt essay Romanens verdensbilde illustrerer Hermann Broch kitschens egenart ved å henvise til bl.a. musikkutøvelsen. Forfatteren ser for seg keiser Nero "som spiller på lutt til sitt fyrverkeri av brennende kristne", hvilket får ham til å tenke på "den spesifikke estet som gjør alt for den skjønne effektens skyld". Broch knytter kitsch-begrepet historisk til det 19. århundres romantiske følelse. Blant dem av det 20. århundres eldre pianistgarde som holdt det gående til langt ut i forrige sekel, var nok Vladimir Horowitz den virtuosen som mer enn noen andre personifiserte 
arven fra romantikken, for Horowitz, som døde i 1989, sto med det tyngste benet solid plantet i den romantisk-sentimentale pianisttradisjonen. Karakteristisk for denne er både en teknisk briljerende spillestil, et populært repertoar og en karismatisk sceneopptreden.

Når Milan Kundera benytter kitsch-betegnelsen i sin bok Romankunsten, er det ikke "den lette kunsten, småkunsten [han setter] opp mot den store kunsten". For "[Hermann] Broch viser at kitschen er noe annet enn bare et verk preget av dårlig smak. ... Det jeg ... avskyr dypt og oppriktig, er Tsjaikovskij, Rachmaninov, Horowitz ved pianoet og de store Hollywoodfilmene". Personlig setter jeg delvis stor pris på både komponistene, pianisten (som den amerikanske komponisten Virgil Thomson kalte "master of distortion and exaggeration") og filmene det er tale om her, men likevel, eller kanskje på grunn av forbeholdet, tror jeg at jeg skjønner hva Kundera prøver å uttrykke. For i kitschen kommer noe uvesentlig og pretensiøst i veien for noe annet, nødvendig. Kundera sikter til tilstedeværelsen av noe nettopp betydningsløst, intetsigende i den kunsten han kritiserer. Og kulturlivets fascinasjon over kunstnerens mindre interessante egenskaper utraderer til tider en kunst som måtte ha noe mer inderlig på hjertet. Bernhards "klaverkunstner"-betegnelse representerer et forsøk på å angi denne andre musikertypen, som på siden av konsertlivets trivialiteter ser seg i stand til å forme en annerledes, unik kunst.

\section{Horowitz i downtown London}

Forsommeren 1982 var en spektakulær tid for det britiske imperiets hovedstad. I midten av juni seiret Thatcher \& Co. i Falklandskrigen, i slutten av mai kom Paven på et historisk besøk til den gamle romerbyen, og på denne tiden gjorde også den levende legenden Vladimir Horowitz, som en klaverspillets Cæsar, et feiende inntog i det londonske konsertlivet. Denne våren var jeg i ferd med å avslutte mitt første studieår hos pianisten Edith Vogel i London. Som øvested brukte jeg iblant Steinwayfabrikkens sentrale lokaler i Conduit Street. En dag måtte jeg imidlertid dra hjem igjen med uforrettet sak. Resepsjonsdamen forklarte at lokalene de neste dagene var reservert for den store Horowitz, som skulle opptre i London, og nå kom han for å finne sitt utvalgte eksemplar. Pianisten var på dette tidspunkt 77 år gammel. I sine velmaktsdager trakk hans blendende teknikk og sceneopptreden unge klaverspirer i hopetall til konsertsalen, hvor de etter beste evne prøvde å studere hemmeligheten bak hans uanstrengte mes- 
terskap. Studiene resulterte etterhvert i en liten epidemi av Horowitz-etterapere, som med tvilsomt resultat gjorde sitt beste for å herme forbildets tempi, dynamiske særegenheter, fraseringer etc. Og nå på sine gamle dager kunne det virke som om Horowitz - slik jeg opplevde ham via TV-skjermen - var i ferd med å prøve samme kunststykke: Å etterligne den yngre utgaven av seg selv.

London var på begynnelsen av 8o-tallet som nå en møteplass for et uoverskuelig antall pianister som strømmet som en laksestim til metropolen for å "(ut)gyte seg for et publikum", for å si det med Thomas Mann. Det var Arrau, Serkin, Gilels, Pollini, Brendel, Ashkenazy, Barenboim og Perahia, foruten ferskere emner fra alle verdens hjørner. Å orientere seg i forhold til dette veldige utbud av klaverspillere, som den norske komponisten Halfdan Kjerulf allerede på 1800-tallet omtalte som "Pianisternes uhyre Sværm", var som å forholde seg til en klaverspillets versjon av bokmessen i Frankfurt. Der presenteres det som kjent mye rart. Og etterhvert som jeg gjennomlevde de psykologiske fasene av nysgjerrighet, fascinasjon, musikalsk metthetsfølelse, tretthet og en snikende resignasjon, begynte jeg å fundere nærmere over "what it was all about".

\section{Kiellermusikk i St Luke's Road}

Anfektelsene fikk utvikle seg over et anselig tidsrom, og oppsto som et logisk resultat av mine soliststudier hos pianisten Edith Vogel, ved Guildhall School of Music and Drama. Vogel (1912-92) var - som Richter og Horowitz - født i Ukraina, men vokste opp i Wien. Hun kom som jødisk flyktning derfra til England i 1938. Oppbruddet ga hennes liv som profesjonell utøver et avbrudd på hele ti år, før hun fikk arbeidstillatelse som musiker. Selv om både Arthur Schnabel og Otto Klemperer i sin tid ønsket å hjelpe henne, var hun i hele denne perioden henvist til å gjøre kontorarbeid og husarbeid m.m. for å tjene til livets opphold.

I løpet av de tre årene mine klaverstudier med Edith Vogel varte, fant undervisningen iblant sted i hennes lille kjellerleilighet i St Luke's Road. Leilighetens spartanske enkelhet, og det faktum at den lå bortgjemt i en mindre attraktiv del av London, illustrerte ytterligere avstanden til Horowitz' verden. Gaten ligger kun en kort spasertur fra Portobello Road, hvor turistene da som nå strømmet til det ukentlige markedet. Når jeg iblant la spaserturen om denne ruten på vei til undervisningen, passerte jeg All Saint's Road, nabogate til St Luke's Road, og beryktet for sin narkotikatrafikk. Jeg avslo alle tilbud høflig, for jeg kjente til 
Aldous Huxleys erfaringer med å lytte til musikk under påvirkning av narkotika, og i The Doors of Perception skriver han (i kontrast til Tiecks optimisme) at å lytte til "instrumental music, oddly enough, left me rather cold". Jeg våget jo heller ikke å tenke på hvordan det ville være å spille slik musikk i alt annet enn edru tilstand, for Vogels undervisningsmåte fordret en varm tilstedeværelse i spillet, med hjernen og alle sanser på plass. Og om nå hennes nabolag kunne virke i tøffeste laget, var damen selv så avgjort like barsk i måten hun formidlet sine musikalske ideer på. Disse var vesensforskjellige fra det meste av det som ble lært bort i metropolen mens jeg studerte der, og når Vogel også spilte som hun lærte, skapte dette en markert avstand til de pedagogisk og kunstnerisk korrekte miljøene. Da jeg første gang møtte henne, hadde jeg for lengst bak meg debutkonsert i Aulaen i Oslo, og følte meg relativt skikket som pianist. Edith Vogel fikk meg fort ned på bakken igjen, og utfordret meg til å starte "fra grunnen av" igjen, som det heter. Det ble et gjensyn med klaverspillets egen kjelleretasje; dets basissfære.

\section{Musikkens ukjente stier}

Jeg kom til å tenke tilbake på mine studieår i London da jeg i 1995 tilfeldig kom over "månedens brev" i BBC Music Magazine. Brevet, som hadde amerikansk adressent, begynte og sluttet slik: "Your monthly CDs have taken me onto musical paths along which I probably would not otherwise have ventured. ... and I probably would not have discovered the artistry of Edith Vogel." Brevskriveren kunne knapt vite at det også i overført betydning lå et atlanterhav mellom denne eksilkunstneren og hennes lokale omgivelser mens hun levde.

Vogels avstand til konvensjonene og Londons musikalske establishment kom til uttrykk på flere måter. Det gjaldt hennes situasjon som eksilkunstner ("I was always the foreigner"), hennes restriktive forhold til det å gi konserter, det at hun var et ikkenavn blant så mange opphaussede celebriteter, og - ikke minst - hennes spillemåte, som på to avgjørende måter skilte seg fra flertallets. Hun insisterte for det første på at klaveret skulle behandles som et orkester, og at musikken i henhold til denne polyfone tenkemåten ble tolket med en bevissthet om alle stemmenes rolle innenfor helheten. Det verste hun visste var det hun omtalte som "høyrehåndspianister", som gjorde melodistemmen overtydelig. Selv dyrket hun frem en kammermusikalsk spillemåte som omfattet såvel den enkelte komposisjonens teksturelle egenart, 
som hensynet til medmusikerne når hun spilte med orkester. Som den kjente musikkskribenten Hans Keller skrev i The Listener i 1985, etter hennes fremføring av Beethovens Korfantasi: "were she a string player, she would be a quartet master. ... she is the only pianist I have ever heard who accepts whatever she plays as being addressed to her."

Denne egenskapen var organisk knyttet til kjepphest nummer to, som var hennes fraseringskunst. Den skydde og opphevet det den amerikanske komponisten Aaron Copland har kalt "the tyranny of the bar line" ("taktstreken(e)s tyranni"). Kundera ser disse vertikale grensepostene mellom tonene som et militant anslag mot livsnerven i musikken: "Jeg har en sann skrekk for å høre mine egne hjerteslag - de minner meg ustanselig om at mine levedager er talte. Derfor har jeg bestandig oppfattet taktstrekene som alle partiturer er overstrødd med, som noe makabert. ... [De store polyfonikernes] kontrapunktiske, horisontale tanke svekker taktinndelingens betydning." Musikere flest oppfatter taktstreker som mentale holdeplasser - eller som Edith Vogel formulerte det: "Everybody at the barline stops thinking. One should always try and go across the bar lines ... Anything that is horisontal should be phrased, ... making it hang together."10 Keller var av den oppfatning at "her legato [forbindelsen mellom tonene] sounds as if it were played on one bow, without interruption." For å frigjøre musikken bak notebildet, måtte taktstrekene, i egenskap av notasjonsmessige gitterstenger, ignoreres og ristes løs, slik kanskje bare ekte eksilkunstnere skjønner det.

\section{Spillets røtter}

Vogel ga svært sjelden konserter, og når hun gjorde det, var den enkelte opptreden for hennes del en begivenhet - "an event", som hun uttrykte det. Hennes oppfatning av den enkeltstående konsertens betydning tangerte det Said mener med "extreme occasion". Hun gjentok hyppig at "I have never been a player". BBCveteranen Stephen Plaistow vedgår at hun i den forstand "was a curious case. She never wanted a busy round of engagements, and the regular touring of recital programs didn't attract her". ${ }^{11}$

Men hun spilte jevnlig i BBC, og hennes godt skjulte tilstedeværelse bak radiomediets vegger, kom uvilkårlig til å gi henne en aura av "den mystiske ukjente" i musikkmetropolen. Plaistow forteller om en ellers godt informert kritiker som - etter å ha

10 Fra intervju i BBC 3, 20/11 1983. 11 BBC Radio 3, 13/9 1996. hørt Vogel fremføre Beethovens Hammerklaversonate - fortørnet spurte ham: "Why don't we know about her?" Plaistow fortsetter: 
"After another Edith Vogel broadcast ... a colleague remarked that anyone turning on the radio and not knowing who was playing would have thought that this was one of the four or five bestknown Beethoven players alive." ${ }^{12}$

Hennes fravær fra både konsertscenen og ekspertenes bevissthet, gjorde hennes virke som musiker til et like ekstremt prosjekt som det konsertritualet hun kun unntaksvis deltok i. Jeg begynte mine studier hos henne høsten 1981, men først etter drøyt to år fikk jeg anledning til å høre henne i konsertsammenheng, da hun opptrådte på en BBC lunchtime concert i St John's Smith Square i London. Dagen etter var jeg svært nysgjerrig på hvordan dette spillet - som hadde vært en form for offentlig oppsummering av to års undervisningsinnhold - ville bli mottatt av den kjente musikkritikeren Nicholas Kenyon i The Times. Det følgende er et utdrag av hans beskrivelse av Edith Vogels fremførelse av Schubert og Schumann:

A problem: to convey in a couple of paragraphs quite how astonishingly different Edith Vogel's playing is from ninetenths of the piano playing one hears these days, ... The sound she makes is unfamiliar, for there is no brittle brilliance or steely impact: every attack is rounded, and sinks into the depths of the keyboard - ... Moreover, and this is a difference from present day taste which has infinite repercussions, she plays from the bottom up ... Vogel's [fremførelse] is grounded in those pulsing, striding bass notes, and in the harmonies they imply. The bass lines are suberbly shaped, and the fantasia-like melodies seem to spring up from the roots. ${ }^{13}$

\section{Avstandens musikk}

I Havaristen nevner Bernhard hvordan Goulds Bach-spill adskilte seg fra alle andres: "slik finnes det ingen annen i hele verden som spiller. ... Spilte så å si nedenfra og opp, ikke som alle andre, ovenfra og ned. Dette var hans hemmelighet." Her er veien kort til Kenyons omtale av Vogel. Lars Amund Vaage er inne på noe av det samme, når han i romanen Rubato lar fortelleren skildre sin klaverlærer som en som "slo akkorder, presise, heilt ned kom han, gjennom himlar, gjennom elementa, ned til det første punktet, deretter til det andre, til botnen". Og Jan Kjærstad har rett når han, med direkte henvisning til Bernhards ord over, skriver at skjønnlitteraturen "eier en mulighet til å formulere originale innsikter om musikk som fagbøkene mangler."

Tilfeldighetene ville at Bernhards Havaristen og Kenyons be-
12 Radio 3 Magazine, December 1983.

13 The Times, 15/11 1983. 
skrivelse av Edith Vogels annerledes spillemåte begge kom på trykk i 1983. Uten å vite om hverandre skrev to musikkjennere det året om det andre spillet, det som kun i korte glimt viser seg på det pianistiske firmamentet. Dette "andre" befinner seg hinsides velklangen, som - forterpet som den er - for lengst har utspilt sin rolle i vår musikkultur, om vi skal tro klaverspilleren i Rubato: "Kven spør lenger etter vakker pianoklang? ... Glenn Gould song, falskt og stygt, for å viska ut, for å knusa det vakre, øydeleggja det, dekka over, for å skaffa seg avstand; han søkte ein kontrast til dei kanoniserte evangeliske konsertar."

Klaverkunstnere som Richter, Gould og Vogel befant seg lysår unna det store flertallet av musikere ved at de bidro til en alternativ, overskridende fortolkningskunst som ledet musikken utenom konsertkulturens konformisme. Vi kan kanskje si at for dem var klaveret "... et middel til å virkeliggjøre musikk, som nok gjør musikken hørbar, men på en halvt uanselig, nesten abstrakt måte og nettopp derfor passer merkverdig godt til musikkens natur", som Thomas Mann skriver om instrumentet. I så fall skulle Goulds Bach-spill ha de beste muligheter, hvis det om noen unevnelige årtusener når frem til de små grønne ørene i fjernere sfærer. Som også vil kunne lytte til daværende president Jimmy Carter, som med lun, dempet røst taler fra platespilleren: "Dette er en gave fra en liten, fjern verden."

\section{LITTERAT UR}

Benestad, Finn: Musikk og tanke, Oslo 1977.

Bernhard, Thomas: Havaristen, Oslo 1994.

Broch, Hermann: Kitsch og kunst, Oslo 1992.

Copland, Aaron: Music \& Imagination, London 1952.

Gombrowicz, Witold: Dagbog 1953-1954, Viborg 1980.

Kjærstad, Jan: Menneskets felt, Oslo 1997.

Kundera, Milan: Romankunsten, Oslo 1987.

Mann, Thomas: Doktor Faustus, Oslo 1969.

Said, Edward W.: Musical Elaborations, London 1992.

Scarpetta, Guy: "Samtidskunst på tvers av alle genre", essay i Aftenposten 18/7-1990. 